\title{
Erythropoietin treatment enhances muscle mitochondrial capacity in humans
}

\author{
Ulla Plenge ${ }^{1}$, Bo Belhage ${ }^{1}$, Amelia Guadalupe-Grau ${ }^{2}$, Peter Riis Andersen ${ }^{3}$, Carsten Lundby ${ }^{4}$, \\ Flemming Dela ${ }^{3}$, Nis Stride ${ }^{4}$, Frank Christian Pott ${ }^{1}$, Jørn W. Helge ${ }^{3}$ and Robert Boushel ${ }^{1,3}$ * \\ 1 Department of Anaesthesia, Bispebjerg Hospital, Copenhagen, Denmark \\ ${ }^{2}$ Department of Physical Education, University of Las Palmas, Gran Canaria, Spain \\ ${ }^{3}$ Department of Biomedical Sciences, Centre for Healthy Aging, University of Copenhagen, Copenhagen, Denmark \\ ${ }^{4}$ Zurich Center for Integrative Human Physiology, University of Zurich Institute of Physiology, Zurich, Switzerland
}

\section{Edited by:}

Kari Kalliokoski, University of Turku,

Finland

Reviewed by:

Jørgen Jensen, Norwegian School of Sport Sciences, Norway

Riikka Kivelä, University of Helsinki,

Finland

\section{*Correspondence}

Robert Boushel, Department of Biomedical Sciences and Department of Anaesthesia, Bispebjerg Hospital Opg 60.1.sal, University of Copenhagen, Bispebjerg Bakke 23, 2400 NV Copenhagen, Denmark. e-mail:boushel@sund.ku.dk
Erythropoietin (Epo) treatment has been shown to induce mitochondrial biogenesis in cardiac muscle along with enhanced mitochondrial capacity in mice. We hypothesized that recombinant human Epo (rhEpo) treatment enhances skeletal muscle mitochondrial oxidative phosphorylation (OXPHOS) capacity in humans. In six healthy volunteers rhEpo was administered by sub-cutaneous injection over 8 weeks with oral iron $(100 \mathrm{mg})$ supplementation taken daily. Mitochondrial OXPHOS was quantified by high-resolution respirometry in saponin-permeabilized muscle fibers obtained from biopsies of the vastus lateralis before and after rhEpo treatment. OXPHOS was determined with the mitochondrial complex I substrates malate, glutamate, pyruvate, and complex II substrate succinate in the presence of saturating ADP concentrations, while maximal electron transport capacity (ETS) was assessed by addition of an uncoupler. rhEpo treatment increased OXPHOS (from $92 \pm 5$ to $\left.113 \pm 7 \mathrm{pmol} \cdot \mathrm{s}^{-1} \cdot \mathrm{mg}^{-1}\right)$ and ETS $\left(107 \pm 4\right.$ to $\left.143 \pm 14 \mathrm{pmol} \cdot \mathrm{s}^{-1} \cdot \mathrm{mg}^{-1}, p<0.05\right)$, demonstrating that Epo treatment induces an upregulation of OXPHOS and ETS in human skeletal muscle.

Keywords: mitochondria, oxidative phosphorylation, rhEPO, muscle, humans

\section{INTRODUCTION}

Erythropoiesis is regulated through activation of the erythropoietin (Epo) receptor (Epo-R) present on erythroid progenitor cells stimulating growth and differentiation of the red blood cell precursors (Jelkmann, 1992). In addition to this, Epo also suppresses plasma volume and thereby effectively controls arterial content (Lundby et al., 2007; Olsen et al., 2011). Epo-R have been observed in several non-hematopoietic tissues and cells such as the liver, pancreas, heart, uterus, central nervous system, vascular endothelium, satellite cells, and skeletal muscle (Farrell and Lee, 2004; Lundby et al., 2008a; Rundqvist et al., 2009; Carraway et al., 2010). The functionality of the Epo- $\mathrm{R}$ in mediating the effect of Epo in non-hematopoietic cells is currently debated (Sinclair et al., 2010), however Epo treatment in the mouse has been found to induce mitochondrial biogenesis in cardiac and skeletal muscle accompanied by an increase in state 3 mitochondrial respiratory capacity (Carraway et al., 2010). Consistent with this pattern, mice electrotransfected with Epo gain less body fat when on a high fat diet as compared to matched control mice (Hojman et al., 2009), and there is some evidence for a shift in skeletal muscle fiber type in mice with Epo treatment (Cayla et al., 2008). In humans no effect on skeletal muscle capillarization, fiber type (Lundby et al., 2008a), and myoglobin (Robach et al., 2009) have been found with rhEpo treatment. Yet, the finding that recombinant human Epo (rhEpo) enhances submaximal endurance performance to a greater extent $(\sim 54 \%)$ than what can be accounted for by increased blood oxygen carrying capacity $(\sim 12 \%)$, and that lactate is lower at a similar relative submaximal exercise intensity after rhEpo treatment
(Thomsen et al., 2007), suggests an additional effect of rhEpo at the metabolic level. The purpose of the present study was hence to test the hypothesis that rhEpo treatment leads to enhanced skeletal muscle mitochondrial oxidative phosphorylation capacity (OXPHOS) in humans.

\section{MATERIALS AND METHODS SUBJECTS}

Six healthy young men aged $21 \pm 2$ years, height $180 \pm 1 \mathrm{~cm}$, weight $73 \pm 2 \mathrm{~kg}$, volunteered to participate in the study. None of the volunteers had been exposed to rhEpo previously. All subjects agreed to maintain their level of physical activity unchanged throughout the trial period. Activity level was monitored throughout the study period with a heart rate monitor (Polar Electro, Finland) worn at all hours of the day except when sleeping. Subjects were informed about the possible risks and discomfort involved before giving their written consent to participate. The study was carried out according to the Declaration of Helsinki and was approved by the Ethical committee of Copenhagen (H-2-2010-104).

\section{RECOMBINANT HUMAN EPO TREATMENT}

The rhEpo treatment aimed to increase the hematocrit (Hct) to $\sim 50 \%$ and to maintain that value throughout the study period. The value of $50 \%$ was chosen, partly from a health perspective to minimize the risk of thrombosis and partly because it is the maximum allowed value in many sports. We treated the subjects with the following regime: 1 week of daily sub-cutaneous (SC) 
injections of 5000 IU of rhEpo (NeoRecormon Roche, Schweiz), followed by 1 week without treatment. Thereafter the subjects were given one weekly SC injection for 7 weeks, titrating the rhEpo dosage (Figure 1) depending on their Hct level (giving either 0,2500 , or $5000 \mathrm{IU})$. The subjects were instructed to take daily iron supplements of $100 \mathrm{mg}$ throughout the study period, starting 2 weeks prior to the rhEpo treatment. Venous blood was drawn to assess blood hematocrit (Radiometer, ABL 800, Denmark) weekly to monitor the Hct value over the course of rhEpo treatment.

\section{PEAK OXYGEN CONSUMPTION}

Expired minute ventilation, $\mathrm{O}_{2}$ fraction, and pulmonary $V \mathrm{O}_{2}$ were measured continuously using an automated metabolic cart (Oxycon Pro, Jaeger, Germany). Subjects performed exercise on an electrically braked cycle ergometer (Ergometrics 800, Jaeger, Germany). The exercise protocol began with a 6 -min warm up period at $60 \mathrm{~W}$ followed by incremental increases in workload by $35 \mathrm{~W}$ each minute until exhaustion.

\section{BODY COMPOSITION (DXA)}

Dual X-ray absorptiometry (DXA) scans were performed before and after the study period for determination of percentage of body fat and lean body mass (Lunar, Madison, WI, USA). Fat free mass and fat mass were expressed as absolute values.

\section{SKELETAL MUSCLE BIOPSIES}

A muscle biopsy was taken prior to the 8 weeks of rhEpo treatment and again 1 week after the treatment period ended. After local anesthesia ( $1 \%$ lidocaine) of the skin and superficial muscle fascia, the biopsy was obtained from the vastus lateralis muscle using the Bergstrøm method. A portion of the obtained muscle tissue was frozen immediately in liquid nitrogen and stored at $-80^{\circ} \mathrm{C}$ for later analysis of citrate synthase (CS) as a mitochondrial matrix marker reflecting mitochondrial content. A small portion of the biopsied muscle was placed in relaxing medium ( $10 \mathrm{mM}$ Ca-EGTA buffer, $0.1 \mu \mathrm{M}$ free calcium, $20 \mathrm{mM}$ imidazole, $20 \mathrm{mM}$ taurine, $50 \mathrm{mM}$

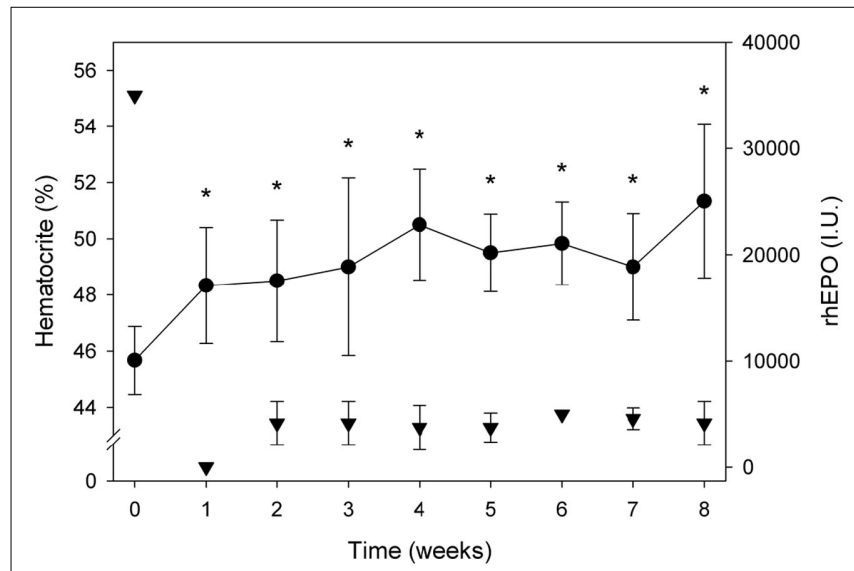

FIGURE 1 | Blood hematocrit (\%) and rhEPO dosage over the 8 week treatment period. Data are means \pm SEM. Asterisk $*$ indicates significant difference pre vs. post, $p<0.05$.
K-MES, 0.5 mM DTT, $6.5 \mathrm{mM} \mathrm{MgCl} 2,5.8 \mathrm{mM}$ ATP, $15 \mathrm{mM}$ phosphocreatine, $\mathrm{pH} 7.1)$ at $2-4^{\circ} \mathrm{C}$. Individual fiber bundles were then separated with forceps to achieve a high degree of fiber separation. The fiber bundles were then permeabilized for $30 \mathrm{~min}$ in $3 \mathrm{ml}$ of ice-cold relaxing medium with saponin $\left(50 \mu \mathrm{g} \cdot \mathrm{ml}^{-1}\right)$. After chemical permeabilization, the tissue was rinsed twice for $10 \mathrm{~min}$ in chilled solution of EGTA $(0.5 \mathrm{mM}), \mathrm{MgCl}_{2} \cdot 6 \mathrm{H}_{2} \mathrm{O}(3 \mathrm{mM})$, K-lactobionate $(60 \mathrm{mM})$, Taurine $(20 \mathrm{mM}), \mathrm{KH}_{2} \mathrm{PO}_{4}(10 \mathrm{mM})$, HEPES $(20 \mathrm{mM})$, sucrose $(110 \mathrm{mM})$, BSA $(1 \mathrm{~g} / \mathrm{l})$, at $\mathrm{pH}$ 7.1. The muscle bundles were then blotted and measured for wet weight in a precision balance. The muscle fibers were then transferred immediately into the respirometer (Oxygraph-2k, Oroboros Instruments, Austria) containing respirometry medium at ambient air saturation at a chamber temperature of $37^{\circ} \mathrm{C}$.

\section{RESPIROMETRY}

Standardized instrumental and chemical calibrations were undertaken on the Oxygraph-2k high-resolution respirometer and applied to correct for back-diffusion of oxygen into the chamber, leak from the exterior, oxygen consumption by the chemical medium and $\mathrm{O}_{2}$ sensor. $\mathrm{O}_{2}$ flux was resolved by software (DatLab 4, Oroboros Instruments, Austria) that calculates non-linear changes in the negative time derivative of the oxygen concentration signal.

All muscle respirometry measurements were done in duplicate. Oxygen diffusion limitation of respiration was prevented by maintaining oxygen levels in the respirometer above air saturation (450-300 $\mathrm{nM}$ range). A substrate-inhibitor titration protocol was applied as follows. Routine respiration (state 2; absence of adenylates) with electron supply of NADH to Complex I was assessed by addition of malate $\left(2 \mathrm{mmol} \cdot \mathrm{l}^{-1}\right)$, followed by titration of pyruvate $\left(10 \mathrm{mmol} \cdot \mathrm{l}^{-1}\right)$, and glutamate $\left(10 \mathrm{mmol} \cdot \mathrm{l}^{-1}\right)$. Coupled state 3 respiration of Complex I was achieved by addition of saturating adenosine-di-phosphate (ADP $5 \mathrm{mmol} \cdot \mathrm{l}^{-1}$ ). Addition of succinate $\left(10 \mathrm{mmol} \cdot \mathrm{l}^{-1}\right)$ then stimulated respiration further through convergent electron input by $\mathrm{FADH}_{2}$ to the Q-junction through complex II to achieve maximal coupled respiration (OXPHOS). Intactness of the outer mitochondrial membrane was tested by quantifying respiration after titration of cytochrome $c\left(10 \mu \mathrm{mol} \cdot \mathrm{l}^{-1}\right)$. Uncoupled respiration and maximal electron transport capacity (ETS) was assessed by addition of carbonyl cyanide- $p$-trifluoromethoxyphenylhydrazone (FCCP) in steps of $0.25 \mathrm{mM}$. The isolated activity of cytochrome oxidase (COX) was measured by addition of $\mathrm{N}, \mathrm{N}, \mathrm{N}^{\prime}, \mathrm{N}^{\prime}$-tetramethyl-1,4benzenediamine, dihydrochloride (TMPD $500 \mu \mathrm{M})+$ ascorbate (2 mM) after antimycin A $(2.5 \mu \mathrm{M})$.

\section{CITRATE SYNTHASE ACTIVITY}

Skeletal muscle tissue was freeze-dried and dissected free of all visible blood, adipose, and connective tissue under a stereomicroscope. Approximately $2 \mathrm{mg}$ of the dissected tissue was homogenized (TissueLyser II, Qiagen, Germany) in $800 \mu \mathrm{l} 0.3 \mathrm{M} \mathrm{K}_{2} \mathrm{HPO}_{4}$, $0.05 \%$ BSA, pH 7.7. Spectrometric determination of CS activity was performed at $25^{\circ} \mathrm{C}$ by 50 times dilution in a solution containing $100 \mu \mathrm{M}$ acetyl-CoA, $0.5 \mathrm{mM}$ NAD (free acid), $1 \mathrm{mM}$ sodium malate, $8 \mu \mathrm{g} \mathrm{ml}^{-1}$ malate dehydrogenase $\left(1200 \mathrm{U} \mathrm{mg}^{-1}\right.$, Boehringer Germany), 2.5 mM EDTA, 10 mM Tris- $\mathrm{HCl}$ (pH 8.0). 


\section{DATA ANALYSIS}

To analyze regulatory characteristics of specific branches of the ETS, several ratio comparisons were made. Physiological Complex I+ II substrate combinations support maximum ETS and OXPHOS capacities due to the additive effect of multiple electron supply pathways converging at the Q-junction. The substrate control ratio (SCR) calculated as the ratio of Complex I to Complex I + II respiratory rate (GMP3/GMPS3) was determined for analysis of the substrate limitation of complex I respiration to maximal coupled mitochondrial respiration. The non-coupled state of maximum respiration (E) was experimentally induced by titration of the uncoupler FCCP to collapse the proton gradient across the mitochondrial inner membrane and thus to measure the capacity of the ETS in the open-circuit operation of respiration. The ratio $P / E$ indicates the extent of limitation of ETS by the phosphorylation system, where a ratio of 1.0 indicates no limitation. The isolated activity of COX measured with ascorbate and TMPD after ETS inhibition by antimycin A was taken as a functional measure of COX enzyme activity in the intact system. All values are given as means \pm SEM for all experiments. A one-way ANOVA was used to detect differences over time during the Epo treatment period. Paired $t$-tests were used to determine differences in mitochondrial OXPHOS and ETS capacity pre-post Epo treatment. For all evaluations, a $p$ value of $<0.05$ was considered significant.

\section{RESULTS}

\section{BLOOD AND EXERCISE RESPONSES}

The mean Hct of the six subjects before rhEpo treatment was $45.7 \pm 0.5 \%$, increasing to $48.3 \pm 0.8 \%$ within 1 week with the $35000 \mathrm{IU}$ dose of rhEpo. After the 8 week intervention period, the mean Hct for the whole group was increased significantly to $51 \pm 1 \%$ (Figure 1). Three of the six subjects received full treatment dosage with a total of 70.000 IU rhEpo over 8 weeks, while two subjects were administered 67.500 and $62.500 \mathrm{IU}$, respectively. The remaining subject exhibited a strong response to the rhEpo injections, and received a total of 50.000 IU. Epo treatment increased $V \mathrm{O}_{2}$ max by $8.3 \pm 2 \%$ from $54 \pm 3$ to $58 \pm 3 \mathrm{ml} \cdot \mathrm{kg}^{-1} \cdot \mathrm{min}^{-1}$ (Table 1). Body composition expressed as BMI and body fat $\%$ was unchanged by rhEpo treatment (Table 1). Compliance to stable activity level during the treatment period was reflected in stable daily and weekly average HR, results not shown.

\section{MITOCHONDRIAL FUNCTION}

After Epo treatment state 3 respiration with Complex I substrates (MPG3) was $52 \pm 5$ before and $64 \pm 7 \mathrm{pmol} \cdot \mathrm{s}^{-1} \cdot \mathrm{mg} \cdot{ }^{1}$

Table 1 | Subject characteristics at baseline and after 8 weeks of rhEpo treatment.

\begin{tabular}{lll}
\hline & Pre & Post \\
\hline Weight $(\mathrm{kg})$ & $73 \pm 2$ & $73 \pm 2$ \\
$\mathrm{BMI}$ & $23 \pm 1$ & $22 \pm 1$ \\
Body fat $(\%)$ & $19 \pm 2$ & $17 \pm 3$ \\
$V \mathrm{O}_{2} \max \left(\mathrm{ml} \cdot \mathrm{kg}^{-1} \cdot \mathrm{min}^{-1}\right)$ & $54 \pm 3$ & $58 \pm 3^{*}$ \\
\hline
\end{tabular}

Data are means \pm SEM.

*Indicates significant difference pre vs post. after rhEpo while respiratory rate for convergent electron supply through the Q-junction for Complex I+ II (Figure 2) increased from $92 \pm 6$ to $113 \pm 7 \mathrm{pmol} \cdot \mathrm{s}^{-1} \cdot \mathrm{mg}^{-1}$. The substrate control ratio (MPG3/MPGS3) was unchanged $(0.56 \pm 0.04$ vs. $0.56 \pm 0.03$ ) by Epo treatment (Table 2 ), while the maximal ETS measured with FCCP titration increased from $107 \pm 4$ to $143 \pm 13 \mathrm{pmol} \cdot \mathrm{s}^{-1} \cdot \mathrm{mg}^{-1}$. The coupling (phosphorylation) control ratio $(P / E)$ reflecting the ratio of OXPHOS to ETS was unchanged (from $0.87 \pm 0.04$ to $0.83 \pm 0.03$ ), indicating similar control of ETS capacity by the OXPHOS system (Table 2). Some of the samples were excluded from statistical analysis due to a high stimulation of respiration by addition of cytochrome $c$. In the baseline experiments one sample showed an increase of respiration of $26 \%$ and in the post Epo experiments 2 samples in different subjects were excluded with responses of 40 and $60 \%$ respectively. For these subjects a single respirometric measurement was used in the analysis. The isolated activity of COX was similar before and after $\left(333 \pm 25 \mathrm{vs} .320 \pm 20 \mathrm{pmol} \cdot \mathrm{s}^{-1} \cdot \mathrm{mg}^{-1}\right)$ Epo treatment, as was CS activity $\left(129 \pm 10\right.$ vs. $\left.139 \pm 13 \mu \mathrm{mol} \cdot \mathrm{g}^{-1} \cdot \mathrm{min}^{-1}, p=0.06\right)$.

\section{DISCUSSION}

The main finding in this study is that rhEpo treatment in humans increased skeletal muscle mitochondrial respiratory capacity. OXPHOS capacity with substrates providing electrons to complex I and II of the electron transport chain was elevated by $22 \%$ with rhEPO treatment (Figure 2). All subjects exhibited an increase in OXPHOS with Epo which represents the maximal ADP-stimulated oxygen consumption linked to the formation of ATP. The increase in whole body $V_{2}$ peak (8\%) was similar to the increase in blood hematocrit (12\%) as found previously (Lundby et al., 2008b), but much smaller than the increase in muscle oxidative capacity.

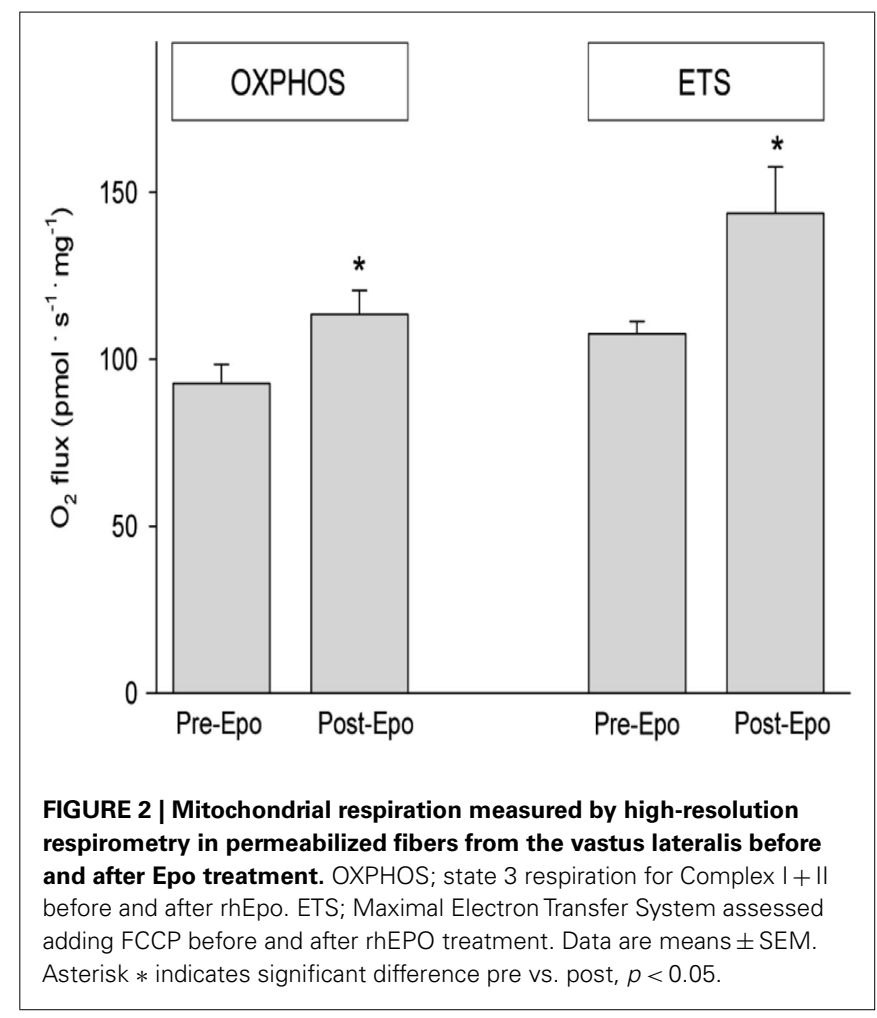


Table 2 | Mitochondrial flux control ratios before and after rhEpo treatment.

\begin{tabular}{lll}
\hline & Pre & Post \\
\hline MPG3/MPGS3 & $0.56 \pm 0.04$ & $0.56 \pm 0.03$ \\
P/E & $0.87 \pm 0.04$ & $0.83 \pm 0.03$ \\
P/CS & $0.73 \pm 0.07$ & $0.83 \pm 0.06$ \\
P/COX & $0.28 \pm 0.01$ & $0.38 \pm 0.04^{*}$ \\
E/COX & $0.33 \pm 0.02$ & $0.45 \pm 0.06^{*}$ \\
\hline
\end{tabular}

MPG3/MPGS3 (M, malate, P, pyruvate, G, glutamate, S, succinate, $3=A D P)$ = substrate control ratio for Complex I: Complex I+ II respiration; P/E = phosphorylation control ratio indicating the ratio of state 3 respiration to maximal electron transport capacity determined by addition of the uncoupler $F C C P ; P / C S=O X P H O S$ relative to citrate synthase activity; $C O X=$ isolated Vmax of cytochrome oxidase measured in the presence of TMPD+ ascorbate and Antimycin A; P/COX = the ratio of coupled state 3 respiration to COX activity; $E / C O X=$ the ratio of ETS to COX activity. Data are means $\pm S E M$.

*Indicates significant difference pre vs post.

This finding is consistent with the concept that humans have an excess capacity of muscle mitochondria over $\mathrm{O}_{2}$ delivery due to limits of cardiac output during whole body exercise (Boushel et al., 2011). In that study peak $V \mathrm{O}_{2}$, cardiac output, limb blood flow, a-v femoral blood gases, $\mathrm{O}_{2}$ diffusion capacity and muscle mitochondrial capacity were measured. For $\mathrm{O}_{2}$ delivery to match muscle mitochondrial capacity during cycling exercise a blood flow increase of $\sim 81 \mathrm{~min}^{-1}$ at peak exercise would be required. The finding of a $22 \%$ increase in mitochondrial OXPHOS in the present study indicates that the disparity between $\mathrm{O}_{2}$ delivery and muscle oxidative capacity is even larger with Epo treatment, and the proportional increase in hematocrit and whole body $V_{2}$ emphasizes the large dependence on $\mathrm{O}_{2}$ delivery.

The non-coupled state of maximum respiration was experimentally induced by titration of the uncoupler FCCP for measurement of the capacity of the ETS, and this $\mathrm{O}_{2}$ flux rate was also increased after rhEpo treatment. Proportional enhancement of the OXPHOS system was reflected in a similar ratio of Complex I vs. complex I+ II respiration (MPG3/MPGS3; Table 2). These findings are consistent with the higher mitochondrial respiratory capacity reported in cardiac muscle of mice (Carraway et al., 2010). That study demonstrated that Epo treatment activates the JAK/STAT, protein kinase $\mathrm{B}$, and eNOS pathways, leading to upregulation of nuclear respiratory factor-1, peroxisome proliferator-activated receptor-coactivator 1 and mitochondrial transcription factor-A gene expression. The Epo-R was required for this response, since Epo-R silencing in cardiomyocytes blocked the Epo-mediated nuclear translocation of nuclear respiratory factor-1. A similar but modest activation of the JAK/STAT pathway by Epo has been demonstrated in human skeletal muscle following acute exercise (Rundqvist et al., 2009).

\section{REFERENCES}

Anderson, E. J., Lustig, M. E., Boyle, K. E., Woodlief, T. L., Kane, D. A., Lin, C. T., Price, J. W. III, Kang, L., Rabinovitch, P. S., Szeto, H. H., Houmard,

We measured the isolated activity of COX as an independent measure of mitochondrial functionality by titrating the redox substrates ascorbate and TMPD following inhibition of the respiratory chain upstream at Complex III with Antimycin A. We found no change in COX activity with rhEpo treatment. Relative to the changes in OXPHOS and ETS, this indicates qualitative changes in mitochondrial function. Traditionally it has been thought that increases in mitochondrial respiratory capacity result from an enlargement of mitochondrial volume rather than by altered intrinsic capacity of mitochondria (Holloszy, 1967; Reichmann et al., 1985; Tonkonogi and Sahlin, 1997; Tonkonogi et al., 1997, 2000). A generally held view is that mitochondrial respiratory capacity is relatively constant at $\sim 5 \mathrm{ml}$ $\mathrm{O}_{2}$ per milliliter of cristae volume (Schwerzmann et al., 1989). However, more recent studies have shown that different lifestyle influences such as acute exercise (Fernström et al., 2004) and high fat diet (Anderson et al., 2009; Skovbro et al., 2011) may change the qualitative properties of mitochondria. This has also been shown in pathological conditions such as type 2 diabetes (Mogensen et al., 2007; Phielix et al., 2008) and chronic obstructive lung disease (Naimi et al., 2011). The intrinsic properties of the mitochondrion are usually determined by relating respiration rate to a measure of mitochondrial content. Five of the six subjects showed an increase in CS activity but statistical significance was not reached $(p=0.06)$. This likely reflects a type 2 error due to the small number of subjects. While mitochondrial volume may also be increased by rhEpo treatment, several independent measures indicate that mitochondrial capacity can be up-regulated independent of changes in mitochondrial volume. The ratios of OXPHOS (P/COX) and ETS (E/COX) to COX activity were significantly elevated, and the OXPHOS capacity expressed per CS activity showed the same directional pattern $(0.84 \pm 0.06$ vs. $0.73 \pm 0.07, p=0.07)$ following rhEpo treatment (Table 2) suggesting a higher mitochondrial respiratory capacity per mitochondria.

In summary, the present results demonstrate that rhEpo treatment induces increases in both blood hematocrit and skeletal muscle mitochondrial respiratory capacity in humans. Proportional increases in OXPHOS with complex I and I + II substrates were found along with a higher electron transport capacity. The present findings extend on previous studies in rodents to demonstrate an upregulation of human skeletal muscle mitochondrial capacity after rhEpo treatment. The findings may have clinical implications for patients with impaired cardiovascular and muscle metabolic disorders.

\section{ACKNOWLEDGMENTS}

This study was supported by the Novo Nordisk Foundation. We would like to thank Dr. Martin Hey-Mogensen for valuable discussion and input on the manuscript. We also thank Jeppe Bach for excellent technical assistance.

rodents and humans. J. Clin. Invest. 119, 573-581.

J. A., Cortright, R. N., Wasserman, D. H., and Neufer, P. D. (2009). Mitochondrial $\mathrm{H} 2 \mathrm{O} 2$ emission and cellular redox state link excess fat intake to insulin resistance in both
Boushel, R., Gnaiger, E., Calbet, J. A., Gonzalez-Alonso, J., WrightParadis, C., Sondergaard, H., Ara, I.,
Helge, J. W., and Saltin, B. (2011). Muscle mitochondrial capacity exceeds maximal oxygen delivery in humans. Mitochondrion 11, 303-307. 
Carraway, M. S., Suliman, H. B., Jones, W. S., Chen, C. W., Babiker, A., and Piantadosi, C. A. (2010). Erythropoietin activates mitochondrial biogenesis and couples red cell mass to mitochondrial mass in the heart. Circ. Res. 106, 1722-1730.

Cayla, J.-L., Maire, P., Duvallet, A., and Wahrmann, J. P. (2008). Erythropoietin induces a shift of muscle phenotype from fast glycolytic to slow oxidative. Int. J. Sports Med. 29, 460-465.

Farrell, F., and Lee, A. (2004). The erythropoietin receptor and its expression in tumor cells and other tissues. Oncologist 9(Suppl. 5), 18-30.

Fernström, M., Tonkonogi, M., and Sahlin, K. (2004). Effects of acute and chronic endurance exercise on mitochondrial uncoupling in human skeletal muscle. J. Physiol. (Lond.) 554(Pt 3), 755-763.

Hojman, P., Brolin, C., Gissel, H., Brandt, C., Zerahn, B., Pedersen, B. K., and Gehl, J. (2009). Erythropoietin over-expression protects against diet-induced obesity in mice through increased fat oxidation in muscles. PLoS ONE 4, e5894. doi:10.1371/journal.pone.0005894

Holloszy, J. O. (1967). Biochemical adaptations in muscle. Effects of exercise on mitochondrial oxygen uptake and respiratory enzyme activity in skeletal muscle. J. Biol. Chem. 242, 2278-2282.

Jelkmann, W. (1992). Erythropoietin: structure, control of production, and function. Physiol. Rev. 72, 449-489.

Lundby, C., Hellsten, Y., Jensen, M. B., Munch, A. S., and Pilegaard, H. (2008a). Erythropoietin receptor in human skeletal muscle and the effects of acute and long-term injections with recombinant human erythropoietin on the skeletal muscle. J. Appl. Physiol. 104, 1154-1160.

Lundby, C., Robach, P., Boushel, R., Thomsen, J. J., Rasmussen, P., Koskolou, M., and Calbet, J. A. (2008b). Does recombinant human
Epo increase exercise capacity by means other than augmenting oxygen transport? J. Appl. Physiol. 105, 581-587.

Lundby, C., Thomsen, J. J., Boushel, R., Koskolou, M., Warberg, J., Calbet, J. A., and Robach, P. (2007). Erythropoietin treatment elevates haemoglobin concentration by increasing red cell volume and depressing plasma volume. J. Physiol. (Lond.) 578(Pt 1), 309-314.

Mogensen, M., Sahlin, K., Fernström, M., Glintborg, D., Vind, B. F., Beck-Nielsen, H., and Højlund, K. (2007). Mitochondrial respiration is decreased in skeletal muscle of patients with type 2 diabetes. Diabetes 56, 1592-1599.

Naimi, A. I., Bourbeau, J., Perrault, H., Baril, J., Wright-Paradis, C., Rossi, A., Taivassalo, T., Sheel, A. W., Rabøl, R., Dela, F., and Boushel, R. (2011). Altered mitochondrial regulation in quadriceps muscles of patients with COPD. Clin. Physiol. Funct. Imaging 31, 124-131.

Olsen, N. V., Aachmann-Andersen, N. J., Oturai, P., Munch-Andersen, T., Bornø, A., Hulston, C., HolsteinRathlou, N. H., Robach, P., and Lundby, C. (2011). Erythropoietin down-regulates proximal renal tubular reabsorption and causes a fall in glomerular filtration rate in humans. J. Physiol. (Lond.) 589(Pt 6), 1273-1281.

Phielix, E., Schrauwen-Hinderling, V. B., Mensink, M., Lenaers, E., Meex, R., Hoeks, J., Kooi, M. E., MoonenKornips, E., Sels, J. P., Hesselink, M. K., and Schrauwen, P. (2008). Lower intrinsic ADPstimulated mitochondrial respiration underlies in vivo mitochondrial dysfunction in muscle of male type 2 diabetic patients. Diabetes 57, 2943-2949.

Reichmann, H., Hoppeler, H., MathieuCostello, O., von Bergen, F., and Pette, D. (1985). Biochemical and ultrastructural changes of skeletal muscle mitochondria after chronic electrical stimulation in rabbits. Pflügers Arch. 404, 1-9.

Robach, P., Recalcati, S., Girelli, D., Gelfi, C., Aachmann-Andersen, N. J., Thomsen, J. J., Norgaard, A. M., Alberghini, A., Campostrini, N. Castagna, A., Viganò, A., Santambrogio, P., Kempf, T., Wollert, K. C., Moutereau, S., Lundby, C., and Cairo, G. (2009). Alterations of systemic and muscle iron metabolism in human subjects treated with lowdose recombinant erythropoietin. Blood 113, 6707-6715.

Rundqvist, H., Rullman, E., Sundberg, C. J., Fischer, H., Eisleitner, K., Ståhlberg, M., Sundblad, P., Jansson, E., and Gustafsson, T. (2009). Activation of the erythropoietin receptor in human skeletal muscle. Eur. J. Endocrinol. 161, 427-434.

Schwerzmann, K., Hoppeler, H., Kayar, S. R., and Weibel, E. R. (1989). Oxidative capacity of muscle and mitochondria: correlation of physiological, biochemical, and morphometric characteristics. Proc. Natl. Acad. Sci. U.S.A. 86, 1583-1587.

Sinclair, A. M., Coxon, A., McCaffery, I., Kaufman, S., Paweletz, K., Liu, L., Busse, L., Swift, S., Elliott, S., and Begley, C. G. (2010). Functional erythropoietin receptor is undetectable in endothelial, cardiac, neuronal, and renal cells. Blood 115, 4264-4272.

Skovbro, M., Boushel, R., Hansen, C. N., Helge, J. W., and Dela, F. (2011). High-fat feeding inhibits exerciseinduced increase in mitochondrial respiratory flux in skeletal muscle. $J$. Appl. Physiol. 110, 1607-1614.

Thomsen, J. J., Rentsch, R. L., Robach, P., Calbet, J. A., Boushel, R., Rasmussen, P., Juel, C., and Lundby, C. (2007). Prolonged administration of recombinant human erythropoietin increases submaximal performance more than maximal aerobic capacity. Eur. J. Appl. Physiol. 101, 481-486.
Tonkonogi, M., Harris, B., and Sahlin, K. (1997). Increased activity of citrate synthase in human skeletal muscle after a single bout of prolonged exercise. Acta Physiol. Scand. 161, 435-436.

Tonkonogi, M., and Sahlin, K. (1997). Rate of oxidative phosphorylation in isolated mitochondria from human skeletal muscle: effect of training status. Acta Physiol. Scand. 161, 345-353.

Tonkonogi, M., Walsh, B., Svensson, M., and Sahlin, K. (2000). Mitochondrial function and antioxidative defence in human muscle: effects of endurance training and oxidative stress. J. Physiol. (Lond.) 528(Pt 2), 379-388.

Conflict of Interest Statement: The authors declare that the research was conducted in the absence of any commercial or financial relationships that could be construed as a potential conflict of interest.

Received: 16 January 2012; accepted: 23 February 2012; published online: 13 March 2012

Citation: Plenge $U$, Belhage $B$, Guadalupe-Grau A, Andersen PR, Lundby C, Dela F, Stride N, Pott FC, Helge JW and Boushel R (2012) Erythropoietin treatment enhances muscle mitochondrial capacity in humans. Front. Physio. 3:50. doi: 10.3389/fphys.2012.00050

This article was submitted to Frontiers in Clinical and Translational Physiology, a specialty of Frontiers in Physiology. Copyright (c) 2012 Plenge, Belhage, Guadalupe-Grau, Andersen, Lundby, Dela, Stride, Pott, Helge and Boushel. This is an open-access article distributed under the terms of the Creative Commons Attribution Non Commercial License, which permits non-commercial use, distribution, and reproduction in other forums, provided the original authors and source are credited. 